\title{
Constitutional Aneuploidy in the Normal Human Brain
}

\author{
Stevens K. Rehen, Yun C. Yung, Matthew P. McCreight, Dhruv Kaushal, Amy H. Yang, Beatriz S. V. Almeida, \\ Marcy A. Kingsbury, Kátia M. S. Cabral, Michael J. McConnell, Brigitte Anliker, Marisa Fontanoz, and Jerold Chun \\ Helen L. Dorris Child and Adolescent Neuropsychiatric Disorder Institute, The Scripps Research Institute, La Jolla, California 92037
}

The mouse brain contains genetically distinct cells that differ with respect to chromosome number manifested as aneuploidy (Rehen et al., 2001); however, the relevance to humans is not known. Here, using double-label fluorescence in situ hybridization for the autosome chromosome 21 (chromosome 21 point probes combined with chromosome 21 "paint" probes), along with immunocytochemistry and cell sorting, we present evidence for chromosome gain and loss in the human brain. Chromosome 21 aneuploid cells constitute $\sim 4 \%$ of the estimated one trillion cells in the human brain and include non-neuronal cells and postmitotic neurons identified by the neuronspecific nuclear protein marker. In comparison, human interphase lymphocytes present chromosome 21 aneuploidy rates of $0.6 \%$. Together, these data demonstrate that human brain cells (both neurons and non-neuronal cells) can be aneuploid and that the resulting genetic mosaicism is a normal feature of the human CNS.

Key words: cerebral cortex; chromosome variation; mosaicism; histochemistry; hybridization; trisomy 21

\section{Introduction}

Aneuploidy is defined as the loss and/or gain of chromosomes to produce a numerical deviation from multiples of the haploid chromosomal complement (King and Stansfield, 1990). It exists in cells of the developing and adult mouse brain (Rehen et al., 2001). Aneuploidy in these cells arises at least in part via chromosome missegregation mechanisms during mitosis (Yang et al., 2003). The existence of aneuploid cells in normal humans is unknown; however, human genetic diseases that produce systemic aneuploidy can affect morphogenesis (Kalousek, 2000) and correlate with the severity of several neurogenetic disorders such as Down's syndrome (Modi et al., 2003), Turner syndrome (Nazarenko et al., 1999), and mosaic variegated aneuploidy syndrome (MVA) (Bitoun et al., 1994). Toward determining the presence of constitutional aneuploidy in the human brain, we report here an analysis of the frequency of chromosome 21 gain and loss among neurons and non-neuronal cells isolated from the cerebral cortex and hippocampus of normal individuals ranging from 2 to 86 years of age. Chromosome 21 was chosen for examination because of the availability of trisomy 21 cells (Bhattacharyya and Svendsen, 2003) that could serve as a positive control for fluorescence in situ hybridization (FISH).

Received Nov. 5, 2004; revised Dec. 21, 2004; accepted Jan. 13, 2005.

This work was supported by the National Institute of Mental Health (J.C.), postdoctoral funding from the Pew Foundation (S.K.R.), predoctoral funding from the Pharmaceutical Research and Manufacturers of America foundation (D.K.), the National Institute of General Medical Sciences (M.J.M., A.H.Y.), and postdoctoral funding from the Swiss National Science Foundation (B.A.). We thank Grace Kennedy for technical help, Cheryl Silao and Alan Saluk from the Scripps Flow Cytometry Core Facility for cell-sorting assistance, and Drs. Anita Bhattacharyya and Clive Svendsen for providing trisomy 21 cells. We declare that we have no competing financial interests.

S.K.R. and Y.C.Y. contributed equally to this work.

Correspondence should be addressed to Dr. Jerold Chun, Department of Molecular Biology, The Scripps Research Institute, 10550 Torrey Pines Road, Institute for Childhood and Neglected Diseases-118, La Jolla, CA 92037. E-mail: jchun@scripps.edu.

D01:10.1523/JNEUROSCI.4560-04.2005

Copyright $\odot 2005$ Society for Neuroscience $\quad$ 0270-6474/05/252176-05\$15.00/0

\section{Materials and Methods}

Tissue collection. Fresh-frozen samples of postmortem brain tissue from normal cerebral cortices and hippocampi were obtained from the Harvard Brain Bank (United States Public Health Service MH/NS 31862) and from the University of Miami/University of Maryland Brain and Tissue Bank (National Institute of Child Health and Human Development NO1-HD-8-3284). Samples were thawed before mincing and incubated in $\mathrm{Ca}^{2+} / \mathrm{Mg}^{2+}$-free PBS supplemented with $2 \mathrm{~mm}$ EGTA for $30-60 \mathrm{~min}$ at $4^{\circ} \mathrm{C}$. After incubation, samples were triturated with a series of $1 \mathrm{ml}$ pipette tips of decreasing diameter, filtered with a $40 \mu \mathrm{m}$ cell filter (BD Biosciences, Bedford, MA), and centrifuged at $500 \times g$ for $5 \mathrm{~min}$. After centrifugation, the supernatant was discarded, and the cell pellet was resuspended in a small volume of PBS. Nuclei were isolated by detergent lysis as described previously and fixed briefly for $15 \mathrm{~min}$ in icecold 1\% paraformaldehyde (Ausubel et al., 1994; Rehen et al., 2001). As a control, metaphase spreads and nuclei from human lymphocytes isolated from a normal 33-year-old male were prepared and analyzed according to standard techniques (Barch et al., 1997). To demonstrate the specificity of the FISH probes with regard to detecting numerical abnormalities of chromosome 21, neural progenitor cells derived from Down's syndrome fetuses (Svendsen et al., 1998; Bhattacharyya and Svendsen, 2003), kindly provided by Dr. Clive N. Svendsen (Waisman Center, University of Wisconsin, Madison, WI), were also analyzed.

FISH probes. FISH "paint" probes against the whole q arm of chromosome 21 and a point probe against a region on the q arm of 21 (21q22.13q22.2) were obtained from Vysis (Downer's Grove, IL). Fluorescence images were captured using a Zeiss Axioskop microscope and Axiocam CCD camera (Carl Zeiss, Thornwood, NY).

Cell sorting and immunocytochemistry. Isolated nuclei from brain samples were blocked for $30 \mathrm{~min}$ in PBS and 2.5\% BSA, washed, and then incubated for $1 \mathrm{~h}$ at room temperature with primary mouse antibody against neuron-specific nuclear protein (NeuN) (1:100; monoclonal antibody 377; Chemicon, Temecula, CA), a known nuclear antigen in neurons (Mullen et al., 1992). Subsequently, NeuN-labeled cells were detected using an Alexa Fluor 488-labeled donkey anti-mouse secondary antibody (1:500; Molecular Probes, Eugene, OR). Nuclei were sorted using the Becton Dickinson (Mountain View, CA) FACSAria system, and the purity of sorted nuclei was confirmed by direct microscope observa- 
tion. FISH was performed as described previously (Rehen et al., 2001; Kaushal et al., 2003).

Data analysis. Between 500 and 1500 cells per human brain sample, as compared with lymphocytes, were hybridized using dual-color FISH, counted by two blinded individuals, and analyzed using Microsoft (Seattle, WA) Excel. To assess the specificity of the FISH probes with regard to detecting numerical abnormalities of chromosome 21, 150 neural progenitor cells derived from Down's syndrome fetuses (Svendsen et al., 1998; Bhattacharyya and Svendsen, 2003) were also counted.

\section{Results}

Chromosome 21 aneuploidy is observed among cells isolated from the normal human brain

FISH was used to examine chromosome number in individual cells in interphase (i.e., cells without condensed chromosomes), as reported previously for brain tissue sections of mouse (Rehen et al., 2001) and diseased human brain (Yang et al., 2001). However, the use of brain sections has the disadvantage of producing partial nuclei or closely apposed nuclei that can result in chromosome loss or gain artifacts, respectively (Rehen et al., 2001; Yang et al., 2001). To eliminate sectioning artifacts, individual brain cell nuclei were isolated for FISH. This population of nuclei consisted of both neural cells (i.e., neurons and glia) and non-neural cells (e.g., endothelial cells and microglia). To identify neuronal nuclei, immunolabeling for NeuN was combined with FISH.

To increase the specificity of chromosome 21 FISH, two distinct kinds of nucleotide probes using different colors were used whereby isolated nuclei were hybridized with a chromosome 21 paint (a mixture of probes specifically against the whole $q$ arm of chromosome 21) and double-labeled with a different-colored probe for 21q22.13-q22.2. Only double-labeled chromosomes were quantified, to reduce the possibility of false-positive and false-negative hybridization signals (Fig. 1A,C).

Control FISH counts on $\sim 1500$ human lymphocyte interphase nuclei (Fig. $1 B$ ) identified rates of aneuploidy of $0.6 \%$ (Table 1), consistent with previously published data in humans (Leach et al., 2004). In addition, FISH specificity for detecting chromosome 21 gain in neural cells derived from Down's syndrome fetuses (Fig. 1C,D, Table 1) validated our enumeration criteria for examining chromosome 21 aneuploidy in the CNS. These control data were analyzed in parallel with $\sim 9000$ interphase nuclei isolated from the cerebral cortex and hippocampus of six normal individuals, which were hybridized and counted using the same protocol applied to control cells (i.e., human lymphocytes and Down's syndrome neural cells). On average, $\sim 93 \%$ of the cells isolated from the brains of individuals ranging from 2 to 86 years of age were disomic for chromosome 21 , whereas $4 \%$ of these cells had gained or lost one copy of chromosome 21 (Table 1). Monosomic, trisomic, and even tetrasomic chromosome 21 cells were present in every brain examined (Fig. $1 E-H$ ). Cells missing both copies or harboring more than four copies of chromosome 21 were not observed in this population. It is noteworthy that the mean copy numbers of chromosome 21 in brain cells and lymphocytes were 2.05 and 2.00, respectively (Table 1), corresponding to a ploidy difference that is likely undetectable by classical methods (Podlisny et al., 1987). This extent of aneuploidy was also observed in preliminary analyses using sex chromosomes and two other autosomes (data not shown). Together, these data demonstrate that millions of aneuploid cells, defined by even a single chromosome, are present in the human brain, regardless of age and in the absence of any documented neurological condition or preexisting disease.
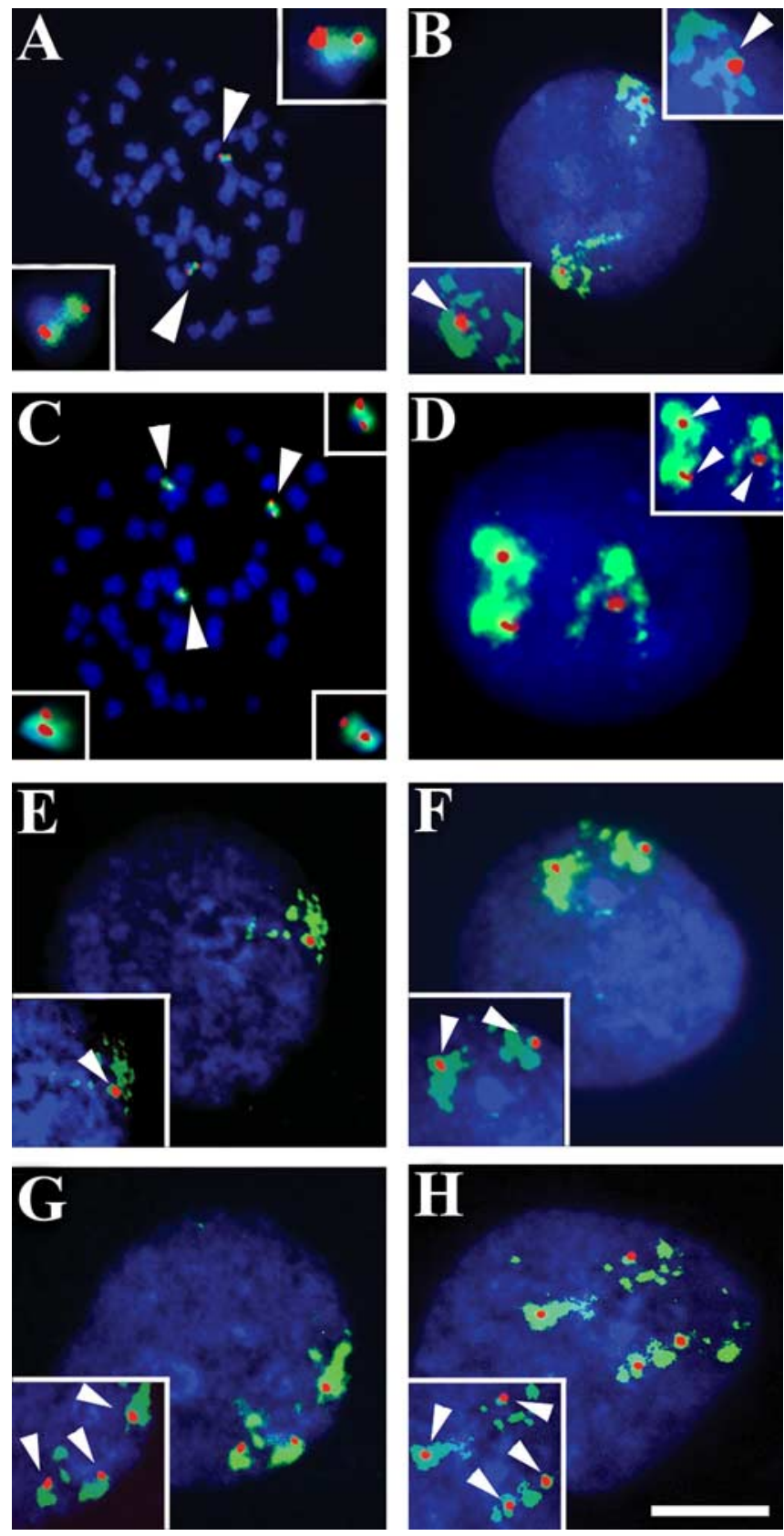

Figure 1. Chromosome 21 gain and loss is observed in cells isolated from the normal human brain. Human lymphocyte labeling demonstrates the specificity of the paint and point probes in metaphase spreads $(\boldsymbol{A})$ and interphase nuclei $(\boldsymbol{B})$. Neural progenitor cells from a Down's syndrome fetus have three copies of chromosome 21, as seen in a metaphase chromosome spread $(\boldsymbol{C})$ and in an interphase nucleus $(\boldsymbol{D})$, demonstrating the sensitivity of the FISH probes with regard to detecting numerical abnormalities of chromosome 21. $\boldsymbol{E}-\boldsymbol{H}$, Nuclei isolated from the brains of different patients containing one $(\boldsymbol{E})$, two $(\boldsymbol{F})$, three $(\boldsymbol{G})$, or four $(\boldsymbol{H})$ copies of chromosome 21. Blue indicates $4^{\prime}$,6-diamidino-2-phenylindole, whole-chromosome paint is shown in green, and the chromosome 21 point probe is shown in red. There is complete overlap between the paint and the point probe, as seen at higher magnification in the insets. Arrowheads indicate the numbers of chromosome 21 per cell. Scale bar, $5 \mu \mathrm{m}$.

\section{Both postmitotic neurons and non-neuronal cells are} aneuploid in the human brain

Glial cells, which represent the majority of brain cells (Pakkenberg et al., 2003), are able to proliferate in some pathological circumstances in the adult brain, whereas postmitotic neurons cannot reenter the cell cycle to proliferate. To determine whether chromosome 21 aneuploidy was present in both postmitotic neu- 
Table 1. Percentages of whole chromosome 21 gain and loss in the brain vary within and among individuals

\begin{tabular}{|c|c|c|c|c|c|c|c|}
\hline \multirow[b]{2}{*}{ Age (years) } & \multirow[b]{2}{*}{ Cell type } & \multirow[b]{2}{*}{ \% Disomy } & \multirow[b]{2}{*}{ \% Tetrasomy } & \multicolumn{2}{|c|}{ Aneuploid karyotype } & \multirow[b]{2}{*}{ \% Aneuploidy } & \multirow[b]{2}{*}{ Mean chromosome number } \\
\hline & & & & $\%$ Monosomy & \% Trisomy & & \\
\hline 2 & Frontal cortex cells & 94.3 & 2.5 & 1.7 & 1.5 & 3.2 & 2.05 \\
\hline 15 & Occipital cortex cells & 93.8 & 2.4 & 2.2 & 1.6 & 3.8 & 2.04 \\
\hline 35 & Frontal cortex cells & 93.9 & 2.4 & 1.8 & 1.8 & 3.6 & 2.05 \\
\hline 48 & Frontal cortex cells & 93.8 & 2.6 & 1.6 & 2.0 & 3.6 & 2.06 \\
\hline 77 & Hippocampal cells & 91.5 & 3.8 & 2.6 & 2.3 & 4.8 & 2.07 \\
\hline 86 & Hippocampal cells & 92.4 & 2.4 & 3.0 & 2.2 & 5.2 & 2.04 \\
\hline Average & Brain cells & 93.3 & 2.7 & 2.1 & 1.9 & 4.0 & 2.05 \\
\hline 33 & Lymphocytes & 99.8 & 0.2 & 0.4 & 0.2 & 0.6 & 2.00 \\
\hline$<0$ & Down's syndrome neural cells & 7.1 & 3.6 & 0 & 89.3 & 89.3 & 2.96 \\
\hline
\end{tabular}

Lymphocytes and Down's syndrome cells were used to validate the counting criteria using chromosome 21 FISH probes.

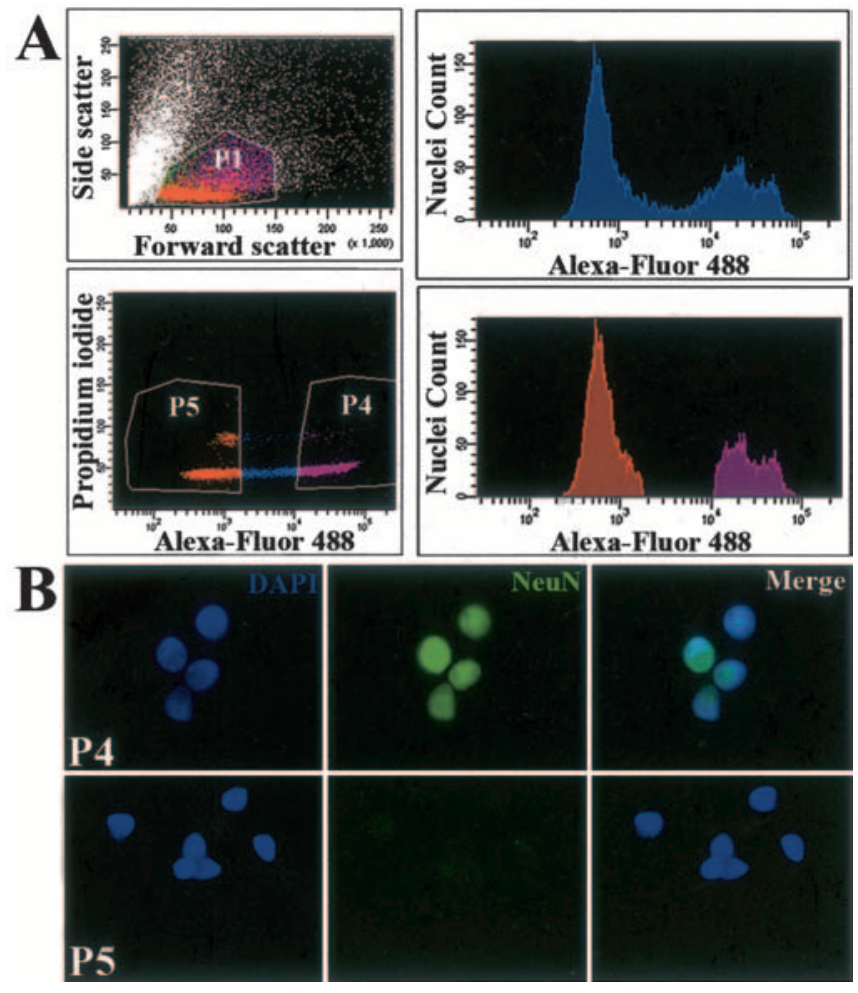

Figure 2. NeuN immunolabeling and cell sorting. $\boldsymbol{A}$, Isolated normal human brain nuclei populations (P1) were gated based on forward scatter and side scatter and gated into $\mathrm{NeuN}+$ (P4) and NeuN - (P5) sort populations based on Alexa Fluor 488 signal. The NeuN + population is generally composed of larger nuclei than $\mathrm{NeuN}$ - nuclei based on forward scatter, although there is a significant size overlap. $\boldsymbol{B}$, A representative preparation of sorted nuclei demonstrating $>99.5 \%$ purity of separation between $\mathrm{NeuN}+(\mathrm{P} 4)$ and $\mathrm{NeuN}-(\mathrm{P} 5)$ populations.

rons and non-neuronal cells in the normal human brain, nuclei isolated from one infant and two adult individuals were incubated with an antibody against NeuN, a known nuclear antigen specific for neurons (Mullen et al., 1992). NeuN-labeled nuclei were then sorted by fluorescence-activated cell sorting (FACS) (Fig. $2 A$ ) to produce $>99.5 \%$ enrichment of NeuN-positive nuclei (Fig. $2 B$ ). These purified populations were then examined by chromosome 21 FISH. From analyses of FACS-purified nuclei, both neurons and non-neuronal cells accounted for the aneuploid population present in the human brain (Table 2), indicating that the mechanisms able to generate chromosome gain and loss may be similar for both cell types (Yang et al., 2003). In summary, these results demonstrate that neurons as well as nonneuronal cells constitute the aneuploid population present in the human brain.

\section{Discussion}

Based on a strategy that combines nuclear isolation, multiprobe FISH, immunocytochemistry, and FACS, the rates of chromosome 21 gain and loss were determined in cells isolated from the brains of normal human individuals. Significant levels of gain and loss were detected, demonstrating that the normal human nervous system contains aneuploid cells. Furthermore, the observation of chromosome 21 gain and loss in NeuN-positive cells supports the view that aneuploid postmitotic neurons may participate in the cortical circuitry of the human brain (Rehen et al., 2001; Kaushal et al., 2003; Yang et al., 2003).

Previous studies of normal murine embryonic brain demonstrated the existence of neural aneuploid cells (Rehen et al., 2001; Kaushal et al., 2003) generated at least in part by chromosomal missegregation mechanisms during mitosis (Yang et al., 2003). The observation of both monosomy and trisomy for chromosome 21 suggests that nondisjunction may account for the generation of aneuploid neurons in the human brain as well.

In view of the existence of aneuploidy in the mouse and human brain, the role or roles of this genome-altering change remain to be determined. It is notable that the $4 \%$ rate of aneuploidy described here is based only on analysis of a single autosome, and in theory, if the loss and gain of whole chromosomes are similar and unbiased for other chromosomes, the overall percentage of aneuploid neurons and aneuploidy in the human brain will be much higher. One hypothetical function of aneuploidy is as a mechanism for generating cellular diversity through chromosomal variation. This is consistent in concept with a recent report describing large-scale copy-number polymorphisms among individuals as a new factor in understanding genomic diversity and disease susceptibilities (Sebat et al., 2004). Our results demonstrate that chromosome copy-number differences produced by aneuploidy can also vary within neuronal populations from single individuals and among individuals, suggesting another layer of systemic genetic complexity. It may also provide a link between aneuploidy and human brain diseases (Heston and Mastri, 1977; Schweber, 1985; Potter, 1991; Yurov et al., 2001), including cases in which certain non-neuronal aneuploid cells in the brains of normal patients may, under appropriate conditions, contribute to brain tumorigenesis (Lengauer et al., 1998).

Constitutive aneuploidy was found at all ages, from infants (age 2, 3.2\% aneuploidy) to young adults (age 15, 3.8\% aneuploidy), through middle age (ages 35 and 48, 3.6\% aneuploidy), and in geriatric samples (ages 77 and $86,4.8 \%$ and 5.2\% aneuploidy, respectively). These data do not rigorously address potential quantitative changes that might occur with age, which would require much larger sample sizes, and do not address the possibility of neuroanatomical differences in aneuploidy rates. By vir- 
Table 2. Percentages of whole chromosome 21 gain and loss in neurons and non-neuronal cells isolated from the brains of three different individuals and sorted by FACS

\begin{tabular}{|c|c|c|c|c|c|c|c|}
\hline \multirow[b]{2}{*}{ Age (years) } & \multirow[b]{2}{*}{ Cell type } & \multirow[b]{2}{*}{ \% Disomy } & \multirow[b]{2}{*}{ \% Tetrasomy } & \multicolumn{2}{|c|}{ Aneuploid karyotype } & \multirow[b]{2}{*}{$\%$ Aneuploidy } & \multirow[b]{2}{*}{ Mean chromosome number } \\
\hline & & & & \% Monosomy & \% Trisomy & & \\
\hline 2 & Neurons & 95.4 & 1.2 & 2.0 & 1.4 & 3.4 & 2.02 \\
\hline 2 & Non-neuronal cells & 95.8 & 0.9 & 2.5 & 0.8 & 3.3 & 2.00 \\
\hline 35 & Neurons & 96.4 & 0.8 & 1.8 & 1.0 & 2.8 & 2.01 \\
\hline 35 & Non-neuronal cells & 95.0 & 1.6 & 2.5 & 0.9 & 3.4 & 2.02 \\
\hline 48 & Neurons & 96.5 & 1.3 & 1.5 & 0.8 & 2.3 & 2.02 \\
\hline 48 & Non-neuronal cells & 94.7 & 1.4 & 3.1 & 0.8 & 3.9 & 2.01 \\
\hline Average & Neurons & 96.1 & 1.1 & 1.8 & 1.1 & 2.8 & 2.0 \\
\hline Average & Non-neuronal cells & 95.2 & 1.3 & 2.7 & 0.8 & 3.5 & 2.0 \\
\hline
\end{tabular}

tue of using FISH probes against chromosome 21, our data can be compared with previous studies of Alzheimer's disease (AD) brains (Herrup and Yang, 2001; Yang et al., 2001) and hypotheses on a relationship between Down's syndrome and AD (Heston and Mastri, 1977; Schweber, 1985; Potter, 1991). As reported for $\mathrm{AD}$, tetrasomic cells could involve cell-cycle re-entering processes associated with neuronal death and would not fit the definition of aneuploidy (Herrup and Yang, 2001; Yang et al., 2001; Herrup and Arendt, 2002; Herrup et al., 2004). The existence of tetrasomic as well as aneuploid cells in normal human brain reported here was not observed previously in normal controls (Yang et al., 2001; Yurov et al., 2001), which likely reflects increased sensitivity of FISH on isolated nuclei used here and/or use of multiple loci probes for a single chromosome. The hypothesis that $\mathrm{AD}$ may involve trisomy 21 is intriguing albeit controversial (Heston and Mastri, 1977; St George-Hyslop et al., 1987) and based primarily on non-neuronal trisomic 21 cells from AD patients (Geller and Potter, 1999). The finding here that trisomic 21 neurons exist in the normal brain, without an obvious relationship to $\mathrm{AD}$, suggests that a basal level of trisomy is not correlated with $\mathrm{AD}$, even in an 86-year-old individual. However, we speculate that a combination of factors, including age [a hint of increased trisomic 21 cells is present in our samples (Table 1)] might increase the relative population of trisomic 21 cells toward approximating a Down's syndrome-like condition that contributes to AD. Future studies using AD brains could assess this possibility.

Increased rates of constitutive aneuploidy in humans could contribute to disruption of normal brain development and/or function. Down's syndrome represents a special case in which chromosome 21 trisomy produces clear CNS defects. A disease producing more pervasive increases in constitutive aneuploidy is MVA, a genetic recessive disorder characterized in part by mosaic aneuploidies, predominantly trisomies and monosomies, and cancer predisposition (Kawame et al., 1999). A recent report (Hanks et al., 2004) identified mutations in the mitotic spindle checkpoint protein, BUBR1, in five MVA families, which indicated a causal link between gain and loss of whole chromosomes and cancer. Coincidentally, MVA is also associated with mental retardation, severe brain anomalies, and microcephaly (Bitoun et al., 1994), and the exacerbation of normal aneuploidy levels may lead to a variety of neural sequelas, including increased neural cell death and/or aborted neurogenesis, which could account for the observed microcephaly. Furthermore, locus triplication of $\alpha$-synuclein is linked to Parkinson's disease (Singleton et al., 2003 ) that could hypothetically be produced by a chromosome 4 trisomy. The relationship between constitutive aneuploidy and increased non-neural cancer predisposition combined with deleterious neural sequelas likely extends to other genes affecting ploidy, as reported for Ataxia-Telangiectasia mutated (McCon- nell et al., 2004). We speculate that a range of normal-throughdiseased neural functions reflect a continuum of quantitative and qualitative aneuploidy differences in the CNS.

\section{References}

Ausubel FM, Brent R, Kingston RE, Moore DD, Seidman JG, Smith JA, Struhl K (1994) Current protocols in molecular biology. New York: Wiley.

Barch MJ, Knutsen T, Spurbeck JL (1997) The AGT cytogenetics laboratory manual. Philadelphia: Lippincott.

Bhattacharyya A, Svendsen CN (2003) Human neural stem cells: a new tool for studying cortical development in Down's syndrome. Genes Brain Behav 2:179-186.

Bitoun P, Martin-Pont B, Tamboise E, Gaudelus J (1994) Optic atrophy, microcephaly, mental retardation and mosaic variegated aneuploidy: a human mitotic mutation. Ann Genet 37:75-77.

Geller LN, Potter H (1999) Chromosome missegregation and trisomy 21 mosaicism in Alzheimer's disease. Neurobiol Dis 6:167-179.

Hanks S, Coleman K, Reid S, Plaja A, Firth H, Fitzpatrick D, Kidd A, Mehes K, Nash R, Robin N, Shannon N, Tolmie J, Swansbury J, Irrthum A, Douglas J, Rahman N (2004) Constitutional aneuploidy and cancer predisposition caused by biallelic mutations in BUB1B. Nat Genet 36:1159-1161.

Herrup K, Arendt T (2002) Re-expression of cell cycle proteins induces neuronal cell death during Alzheimer's disease. J Alzheimers Dis 4:243-247.

Herrup K, Yang Y (2001) Pictures in molecular medicine: contemplating Alzheimer's disease as cancer: a loss of cell-cycle control. Trends Mol Med 7:527.

Herrup K, Neve R, Ackerman SL, Copani A (2004) Divide and die: cell-cycle events as triggers of nerve cell death. J Neurosci 24:9232-9239.

Heston LL, Mastri AR (1977) The genetics of Alzheimer's disease: associations with hematologic malignancy and Down's syndrome. Arch Gen Psychiatry 34:976-981.

Kalousek DK (2000) Pathogenesis of chromosomal mosaicism and its effect on early human development. Am J Med Genet 91:39-45.

Kaushal D, Contos JJ, Treuner K, Yang AH, Kingsbury MA, Rehen SK, McConnell MJ, Okabe M, Barlow C, Chun J (2003) Alteration of gene expression by chromosome loss in the postnatal mouse brain. J Neurosci 23:5599-5606.

Kawame H, Sugio Y, Fuyama Y, Hayashi Y, Suzuki H, Kurosawa K, Maekawa K (1999) Syndrome of microcephaly, Dandy-Walker malformation, and Wilms tumor caused by mosaic variegated aneuploidy with premature centromere division (PCD): report of a new case and review of the literature. J Hum Genet 44:219-224.

King RC, Stansfield WD (1990) A dictionary of genetics, Ed 4. New York: Oxford UP.

Leach NT, Rehder C, Jensen K, Holt S, Jackson-Cook C (2004) Human chromosomes with shorter telomeres and large heterochromatin regions have a higher frequency of acquired somatic cell aneuploidy. Mech Ageing Dev 125:563-573.

Lengauer C, Kinzler KW, Vogelstein B (1998) Genetic instabilities in human cancers. Nature 396:643-649.

McConnell MJ, Kaushal D, Yang AH, Kingsbury MA, Rehen SK, Treuner K, Helton R, Annas EG, Chun J, Barlow C (2004) Failed clearance of aneuploid embryonic neural progenitor cells leads to excess aneuploidy in the Atm-deficient but not the Trp53-deficient adult cerebral cortex. J Neurosci 24:8090-8096.

Modi D, Berde P, Bhartiya D (2003) Down syndrome: a study of chromosomal mosaicism. Reprod Biomed Online 6:499-503. 
Mullen RJ, Buck CR, Smith AM (1992) NeuN, a neuronal specific nuclear protein in vertebrates. Development 116:201-211.

Nazarenko SA, Timoshevsky VA, Sukhanova NN (1999) High frequency of tissue-specific mosaicism in Turner syndrome patients. Clin Genet 56:59-65.

Pakkenberg B, Pelvig D, Marner L, Bundgaard MJ, Gundersen HJ, Nyengaard JR, Regeur L (2003) Aging and the human neocortex. Exp Gerontol 38:95-99.

Podlisny MB, Lee G, Selkoe DJ (1987) Gene dosage of the amyloid $\beta$ precursor protein in Alzheimer's disease. Science 238:669-671.

Potter H (1991) Review and hypothesis: Alzheimer disease and Down syndrome-chromosome 21 nondisjunction may underlie both disorders. Am J Hum Genet 48:1192-1200.

Rehen SK, McConnell MJ, Kaushal D, Kingsbury MA, Yang AH, Chun J (2001) Chromosomal variation in neurons of the developing and adult mammalian nervous system. Proc Natl Acad Sci USA 98:13361-13366.

Schweber M (1985) A possible unitary genetic hypothesis for Alzheimer's disease and Down syndrome. Ann NY Acad Sci 450:223-238.

Sebat J, Lakshmi B, Troge J, Alexander J, Young J, Lundin P, Maner S, Massa H, Walker M, Chi M, Navin N, Lucito R, Healy J, Hicks J, Ye K, Reiner A, Gilliam TC, Trask B, Patterson N, Zetterberg A, et al. (2004) Large-scale copy number polymorphism in the human genome. Science 305:525-528.

Singleton AB, Farrer M, Johnson J, Singleton A, Hague S, Kachergus J, Huli- han M, Peuralinna T, Dutra A, Nussbaum R, Lincoln S, Crawley A, Hanson M, Maraganore D, Adler C, Cookson MR, Muenter M, Baptista M, Miller D, Blancato J, et al. (2003) $\alpha$-Synuclein locus triplication causes Parkinson's disease. Science 302:841.

St George-Hyslop PH, Tanzi RE, Polinsky RJ, Neve RL, Pollen D, Drachman D, Growdon J, Cupples LA, Nee L, Myers RH, O'Sullivan D, Watkins PC, Amos JA, Deutsch CK, Bodfish JW, Kinsbourne M, Feldman RG, Bruni A, Amaducci L, Foncin J-F, et al. (1987) Absence of duplication of chromosome 21 genes in familial and sporadic Alzheimer's disease. Science 238:664-666.

Svendsen CN, ter Borg MG, Armstrong RJ, Rosser AE, Chandran S, Ostenfeld T, Caldwell MA (1998) A new method for the rapid and long-term growth of human neural precursor cells. J Neurosci Methods 85:141-152.

Yang AH, Kaushal D, Rehen SK, Kriedt K, Kingsbury MA, McConnell MJ, Chun J (2003) Chromosome segregation defects contribute to aneuploidy in normal neural progenitor cells. J Neurosci 23:10454-10462.

Yang Y, Geldmacher DS, Herrup K (2001) DNA replication precedes neuronal cell death in Alzheimer's disease. J Neurosci 21:2661-2668.

Yurov YB, Vostrikov VM, Vorsanova SG, Monakhov VV, Iourov IY (2001) Multicolor fluorescent in situ hybridization on post-mortem brain in schizophrenia as an approach for identification of low-level chromosomal aneuploidy in neuropsychiatric diseases. Brain Dev 23 [Suppl 1]:S186-S190. 